Received 00th January 20xx, Accepted 00th January 20xx

DOI: $10.1039 / x 0 x \times 00000 x$

www.rsc.org/

\section{High hole mobility and light-harvesting in discotic nematic dendrimers prepared via 'click' chemistry}

\author{
Alberto Concellón,,$^{\mathrm{a}, \ddagger}$ Roberto Termine, ${ }^{\mathrm{b}}$ Attilio Golemme, ${ }^{\mathrm{b}}$ Pilar Romero, ${ }^{\mathrm{a}}$ Mercedes Marcos, ${ }^{\mathrm{a}}$ and \\ José Luis Serrano*,a,b
}

We report a new family of liquid crystalline porphyrin-core dendrimers with coumarin units at the periphery of the dendrimer. These compounds have been prepared by copper-catalyzed azide-alkyne "click" cycloaddition (CuAAC). The mesomorphic properties have been investigated by polarized optical microscopy (POM), differential scanning calorimetry (DSC) and X-ray diffraction (XRD). The peripheral coumarin units play a key role in the liquid crystal behavior, contributing to the appearance of discotic nematic mesophases with hole mobility values among the highest values reported for discotic liquid crystals (of the order of $1 \mathrm{~cm}^{2} \cdot \mathrm{V}^{-1} \cdot \mathrm{s}^{-1}$ ). It has also been demonstrated that excitation of the coumarin moieties leads to energy transfer (antenna effect) to the luminescent porphyrin core. Therefore, this strategy, that involves 'click' chemistry, has proven to be a powerful and elegant synthetic tool for the preparation of optoelectronic materials based on complex dendritic architectures.

\section{Introduction}

In the last few years the research field of organic electronics i.e. the use of conjugated molecules as active components in electronic devices- has expanded impressively and diversified into organic light-emitting diodes (OLEDs), organic field-effect transistors (OFETs) or organic photovoltaic devices (OPVs). The ideal organic semiconductor must have closely-packed molecules with few defects between molecules or domains because charge transport depends on molecular order. ${ }^{1-4}$ The highest charge carrier mobility in organic systems has been measured in single crystals of pentacene and rubrene (20 $\left.\mathrm{cm}^{2} \mathrm{~V}^{-1} \mathrm{~s}^{-1}\right),{ }^{5}$ but the preparation of single-crystalline thin films is very tedious and not applicable industrially. To overcome this limitation, liquid crystals (LCs) offer an interesting approach as they self-organize into nanostructured phases that provide properties similar to those of organic single crystals, while the dynamics is vital for the processability and the self-healing of structural defects. ${ }^{6-14}$ In particular, columnar LCs have attracted considerable attention because they represent one-dimensional charge carrier pathways, whereby the inner aromatic core is conducting and the outer alkyl periphery has an insulating character. In such phases, charge mobilities of the order of $1 \mathrm{~cm}^{2} \cdot \mathrm{V}^{-1} \cdot \mathrm{s}^{-1}$ along the direction of

\footnotetext{
a. Instituto de Ciencia de Materiales de Aragón, Departamento de Química Orgánica, Universidad de Zaragoza-CSIC, 50009 Zaragoza, Spain.

b. LASCAMM CR-INSTM, CNR-NANOTEC Lab LiCryL, Dipartimento di Fisica, Universitá della Calabria, 87036 Rende, Italy.

c. Instituto de Nanociencia de Aragón, Departamento de Química Orgánica, Universidad de Zaragoza, 50009 Zaragoza, Spain.

* Present adress: Department of Chemistry, Massachusetts Institute of Technology, MA 02139, Cambridge, United States.
}

the columns have been described. ${ }^{15-19}$ Despite this promising properties, columnar mesophases still suffer from the disadvantage that orientationally uniform domains that are large enough to be used in most devices are often hard to obtain. Nonetheless, very recently we reported a new family of LC dendrimers with charge mobilities of the same order of magnitude as those found in columnar phases, in spite of exhibiting a discotic nematic $\left(N_{D}\right)$ phase. ${ }^{20}$ The $N_{D}$ mesophase makes possible to obtain large homogeneously oriented domains with very low density of defects due to its lower order degree in comparison to columnar mesophases.

On the other hand, LC dendrimers have been recognized as an attractive tool for the preparation of polymeric materials for optoelectronic applications. ${ }^{21-24}$ They combine in the same molecule the structural and synthetic versatility of dendrimers with the anisotropic properties of the LC state. The topology of these molecules bearing several external reactive groups allows the introduction of different active moieties that selfassemble into a LC arrangement with a supramolecular order that facilitates charge transport. ${ }^{25-29}$ Although the preparation of dendrimers has been improved over the past decade, their synthesis requires extremely efficient reactions. "Click" chemistry provides efficient routes for the synthesis of dendritic structures because it requires mild reaction conditions, tolerates a wide range of functional groups, and leads to high yields. ${ }^{30-34}$

The aim of the work reported here is to exploit the 'click' chemistry as an effective and elegant approach for the preparation of LC dendrimers with potential applications in organic optoelectronic devices. Herein, we describe a new approach which allows us to connect four azido-functionalized dendrons with an alkyne functionalized porphyrin core. This 
strategy gives high yields and resulted in products that can be easily purified by non-chromatographic procedures.

Following this synthetic approach, three porphyrin-core dendrimers have been synthetized and their chemical structure are shown in Figure 1. Two of them are the first- and second-generation dendrimers bearing coumarin moieties

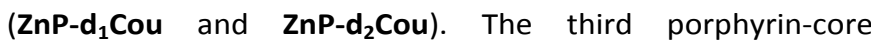

dendrimer was prepared to evaluate the role of coumarip peripheral units in these supermoleculapsystemp. by a first-generation dendron containing dodecyloxy alkyl

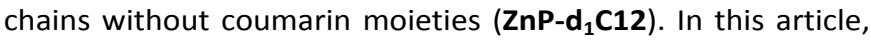
we report the synthesis, chemical and physical characterization of these porphyrin-core dendrimers, with the aim of assessing their possible use in organic electronics.
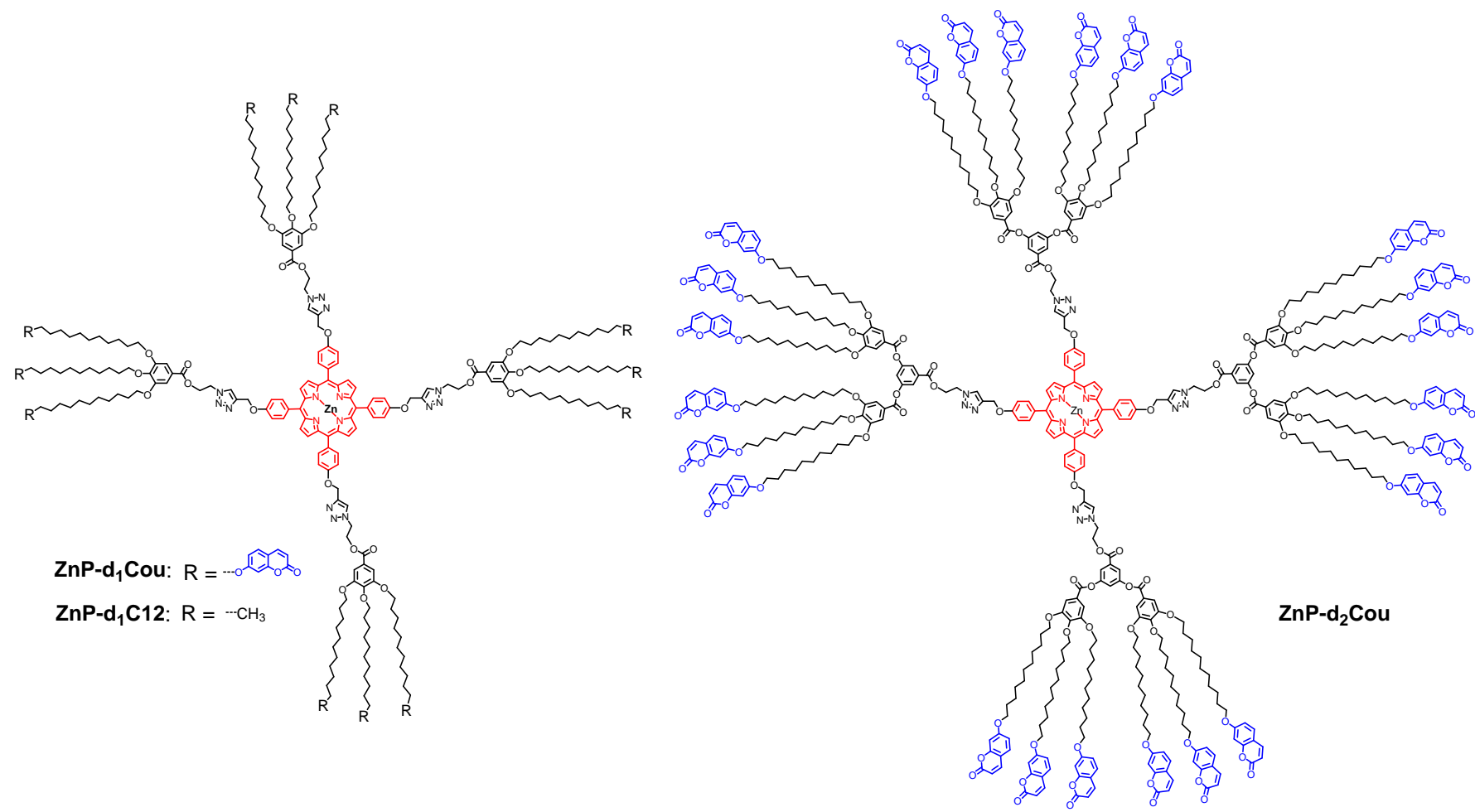

Figure 1. Chemical structure of the porphyrin-core dendrimers prepared by 'click' chemistry.

\section{Results and discussion}

\section{Synthesis and structural characterization}

The synthesis of the azido functionalized dendrons $\left(\mathbf{N}_{3}-\mathbf{d}_{\mathbf{1}} \mathbf{C o u}\right.$, $\mathbf{N}_{3}-\mathbf{d}_{\mathbf{2}} \mathbf{C o u}$, and $\mathbf{N}_{\mathbf{3}}-\mathbf{d}_{\mathbf{1}} \mathbf{C 1 2}$ ) and the alkyne functionalized porphyrin core (ZnP-YNE) was described in the Supporting Information.

A convergent synthetic approach was used for the preparation of the porphyrin-core dendrimers (Scheme 1). In the final synthetic step, the azido functionalized dendrons and the alkyne functionalized porphyrin were coupled by coppercatalyzed azide-alkyne cycloaddition (CUAAC) using THF/water as solvent and $\mathrm{CuSO}_{4} \cdot 5 \mathrm{H}_{2} \mathrm{O} /$ sodium ascorbate as the catalytic system. An excess of the azide dendron (1.5 equivalents per alkyne group) was employed to ensure the completeness of the reaction and was removed by using a previously synthesized alkyne-functionalized Wang resin. The efficiency of the CuAAC coupling was determined by FTIR, NMR spectroscopy (Figure 2a and Figures S1-S10), MALDI-TOF MS (Figures S11-S13), and size exclusion chromatography (SEC). All characterization methods indicated that the target porphyrincore dendrimers were monodisperse.

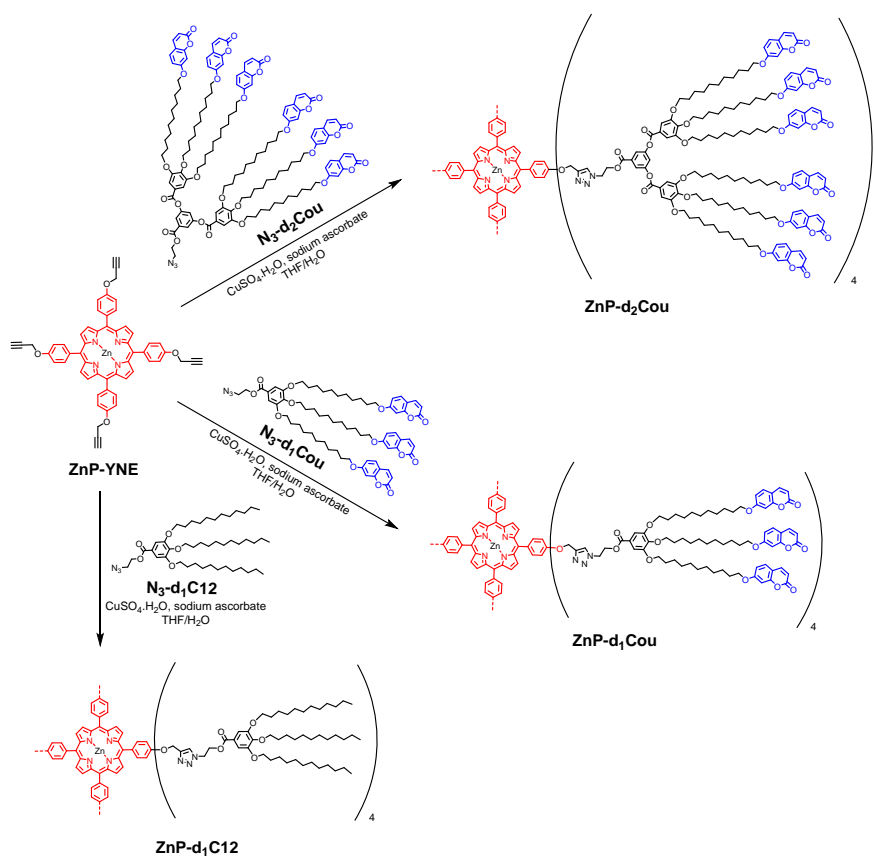

Scheme 1. Convergent synthetic approach used for the preparation of the porphyrin-core dendrimers. 
(a)

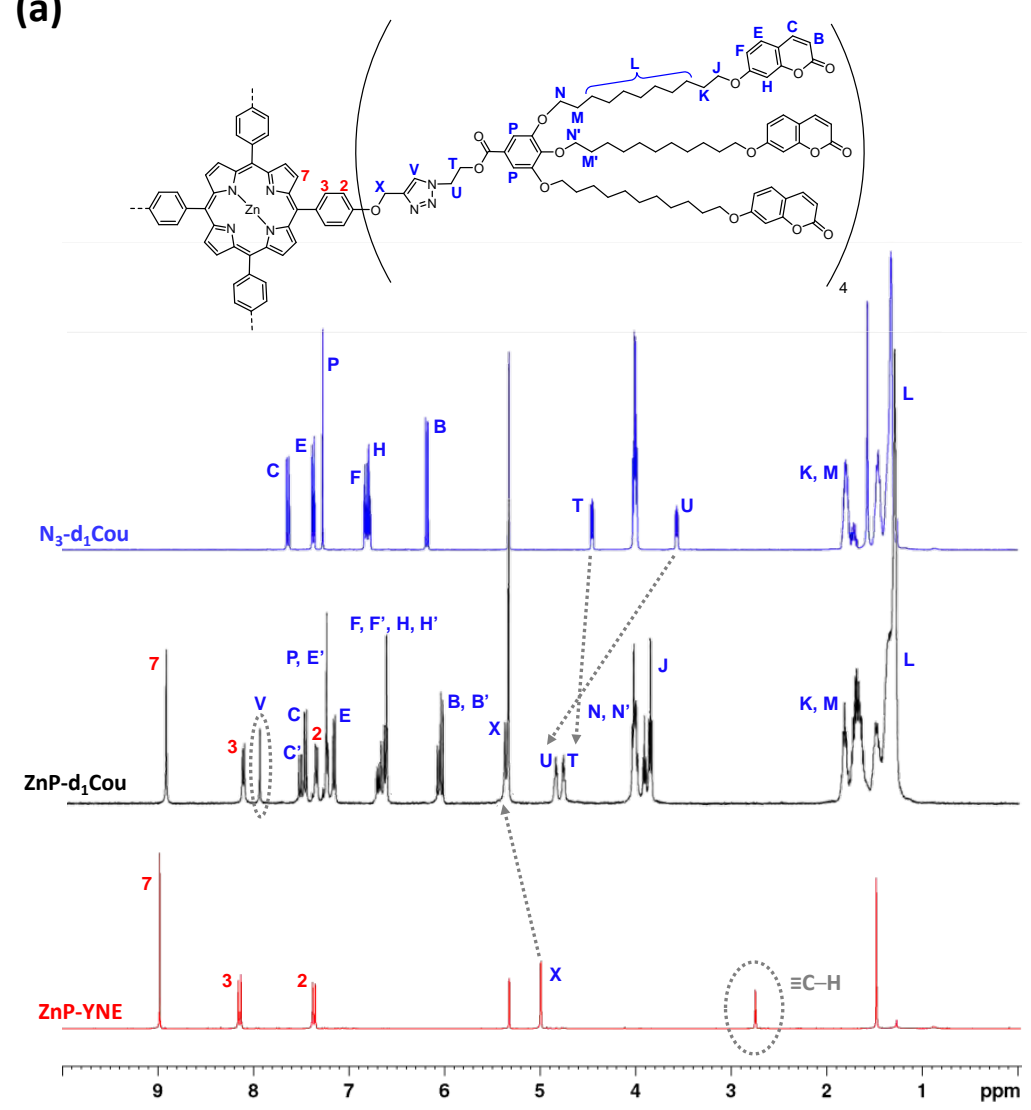

(b)

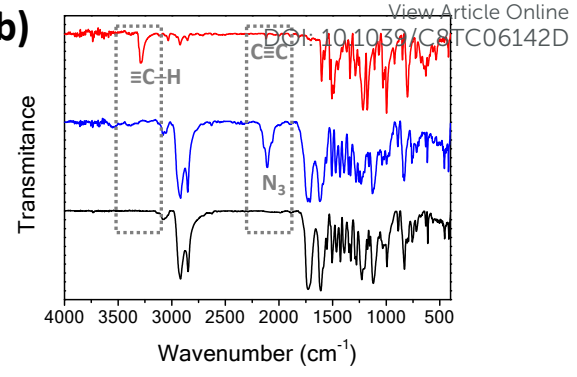

(c)

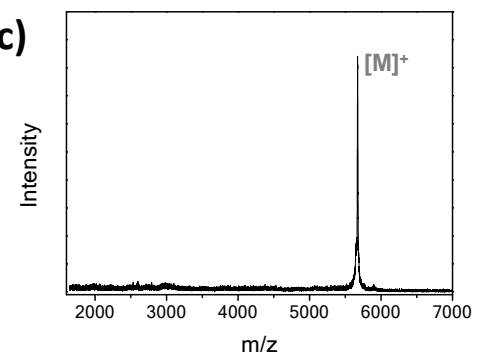

(d)

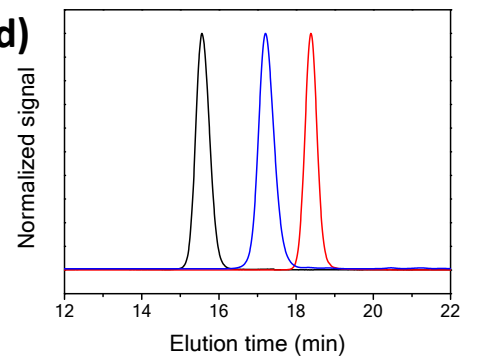

Figure 2. (a) ${ }^{1} \mathrm{H}$ NMR spectra $\left(400 \mathrm{MHz}, \mathrm{CD}_{2} \mathrm{Cl}_{2}, 298 \mathrm{~K}\right)$, (b) FTIR spectra, (c) MALDI mass spectrum, (d) SEC traces of ZnP-YNE (red), ZnP-d $\mathbf{d}_{1} \mathrm{Cou}$ (black) and $\mathbf{N}_{\mathbf{3}}-\mathbf{d}_{1} \mathrm{Cou}$ (blue).

Evidence for the formation of the dendrimers was collected from the ${ }^{1} \mathrm{H}$ NMR spectra (Figure 2a), where new peaks corresponding to the formed triazol ring appeared at around $7.95 \mathrm{ppm}\left(H_{\mathrm{V}}\right)$ and the ethynyl proton signal of the alkyne functionalized porphyrin core disappeared upon CuAAC coupling. Furthermore, there were changes in the ${ }^{1} \mathrm{H}$ shift of the methylenic protons linked to the new formed triazol $\left(H_{U}\right.$ and $H_{T}$ ).

FTIR spectra also confirmed the coupling, the bands at around $3280(\equiv \mathrm{C}-\mathrm{H}), 2120(\mathrm{C} \equiv \mathrm{C})$ and $2110\left(\mathrm{~N}_{3}\right)$ disappeared after the CUAAC reaction (Figure $\mathbf{2 b}$ ). Further confirmation of the coupling was provided by SEC analysis and MALDI-TOF mass spectroscopy. The MALDI-TOF mass spectra showed the expected peak and no other signals corresponding to dendrimers with a partial functionalization were detected (Figure 2c). The SEC curves showed monomodal molar mass distributions and residual precursors were not detected (Figure 2d). As can be observed, CuAAC coupling of the precursors blocks gave rise to a shift of the molar mass distribution towards lower retention times that indicates the porphyrin-core dendrimers' formation.

\section{Thermal stability and liquid crystalline properties}

The thermal stability of all the compounds was studied by TGA. All of the samples showed good thermal stability with the $2 \%$ weight loss temperature $\left(T_{2 \%}\right)$ more than 150 o $C$ above the clearing point (Table 1). Thermal transitions and mesomorphic properties were studied by POM, DSC and XRD, and the results are listed in Table 1. Three cycles were carried out in DSC experiments and data were taken from the second cycle. In some cases, temperatures were taken from POM observations because transition peaks were not detected in DSC curves (Figures S14-S17).

Table 1. Thermal Stability and Transition Temperatures.

\begin{tabular}{|c|c|c|}
\hline & $\mathrm{T}_{2 \%}\left({ }^{\circ} \mathrm{C}\right)^{[\mathrm{a}]}$ & Phase transitions ${ }^{[b]}$ \\
\hline $\mathrm{N}_{3}-\mathrm{d}_{1} \mathrm{Cou}$ & 213 & g $20 \mathrm{Cr} 61 \mathrm{I}$ \\
\hline $\mathrm{N}_{3}-\mathrm{d}_{2} \mathrm{Cou}$ & 230 & 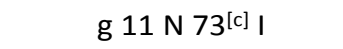 \\
\hline$N_{3}-d_{1} C 12$ & 241 & $\mathrm{Cr} 30 \mathrm{I}$ \\
\hline $\mathrm{ZnP}-\mathrm{d}_{1} \mathrm{Cou}$ & 344 & g $24 \mathrm{~N}_{\mathrm{D}} 112^{[\mathrm{c}]}$ | \\
\hline $\mathrm{ZnP}-\mathrm{d}_{2} \mathrm{Cou}$ & 309 & g $21 \mathrm{~N}_{\mathrm{D}} 98^{[\mathrm{c}]}$ । \\
\hline $\mathrm{ZnP}-\mathrm{d}_{1} \mathrm{C} 12$ & 335 & $\mathrm{~g} 122 \mathrm{Cr} 151^{[\mathrm{c}]} \mathrm{M} 155^{[\mathrm{c}]}$ \\
\hline
\end{tabular}

[a] Temperature at which $2 \%$ mass lost is detected in the thermogravimetric curve. [b] DSC data of the second heating process at a rate of $10{ }^{\circ} \mathrm{C} / \mathrm{min}$. Temperatures are read at the maximum of the peak. g: glass, $\mathrm{Cr}$ : crystal, $\mathrm{N}$ : nematic mesophase, $N_{D}$ : discotic nematic mesophase, $M$ : unidentified mesophase, I: isotropic liquid. [c] POM data. 
Only the azido-functionalized second generation dendron $\left(\mathbf{N}_{\mathbf{3}}-\right.$ $\mathbf{d}_{\mathbf{2}} \mathbf{C o u}$ ) exhibited LC behavior. The other azido-functionalized dendrons $\left(\mathbf{N}_{\mathbf{3}}-\mathbf{d}_{\mathbf{1}} \mathrm{Cou}\right.$ and $\left.\mathbf{N}_{\mathbf{3}}-\mathbf{d}_{\mathbf{1}} \mathbf{C 1 2}\right)$ were not mesomorphic. $\mathbf{N}_{\mathbf{3}}-\mathbf{d}_{\mathbf{2}}$ Cou showed a birefringent texture by POM at room temperature on applying mechanical stress (Figure $\mathbf{3 a}$ ).
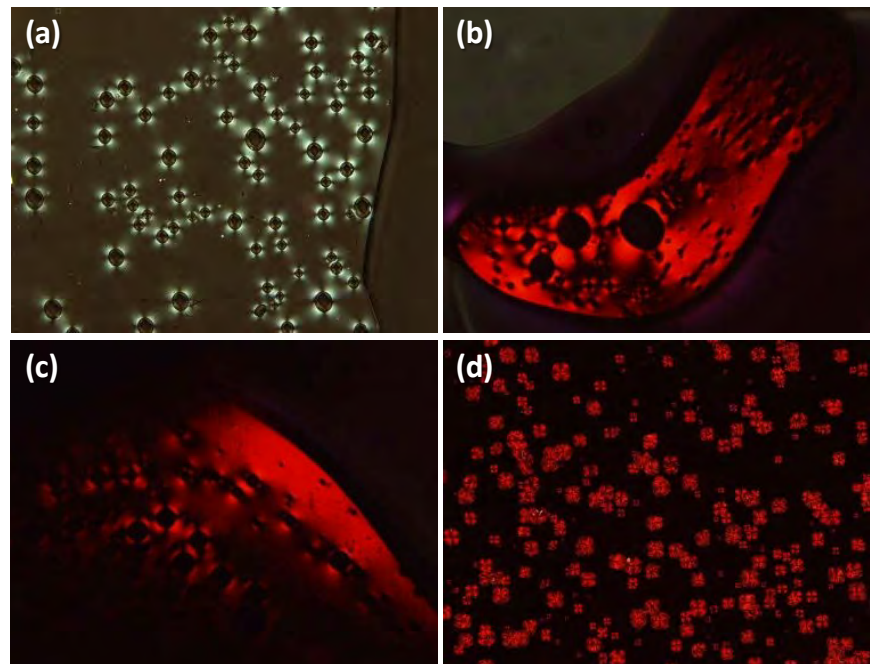

Figure 3. POM microphotographs for: (a) $\mathbf{N}_{\mathbf{3}}-\mathbf{d}_{\mathbf{2}} \mathbf{C o u}$ taken at room temperature in the second cooling process, (b) $\mathrm{ZnP}$ $\mathbf{d}_{\mathbf{1}}$ Cou taken at room temperature in the second cooling, (c) ZnP-d $\mathbf{d}_{\mathbf{2}} \mathbf{C o u}$ taken at room temperature in the second cooling process, and (d) $\mathbf{Z n P}-d_{1} \mathbf{C 1 2}$ at 152 oC in the second heating process.

All the porphyrin-core dendrimers exhibited mesogenic properties and the thermal behavior was different depending on the compound. In the case of the porphyrin-core dendrimers with coumarin functional units around the porphyrin core (ZnP-d $\mathbf{d}_{\mathbf{1}} \mathbf{C o u}$, and $\left.\mathbf{Z n P - d _ { 2 }} \mathbf{C o u}\right)$, enantiotropic LC mesophases were observed. The DSC curves showed only a glass transition freezing the mesomorphic order at room temperature, while clearing temperatures were established from POM observations. All the compounds had a high tendency to homeotropic alignment and the mesophase was observed by POM on applying mechanical stress to the samples showing birefringent textures (Figure 3).

The assignment of the mesophase type was carried out by XRD. The XRD pattern of the coumarin-containing second generation dendron $\left(\mathbf{N}_{\mathbf{3}}-\mathbf{d}_{\mathbf{2}} \mathbf{C o u}\right)$ showed only diffuse scattering, suggesting the absence of long-range positional order in the LC phase (Figure S18). This kind of pattern corresponds to a nematic mesophase which has only orientationalieorder this

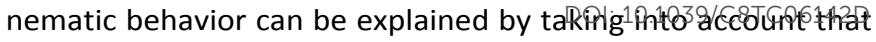
the flexibility of the ester bonds allows adopting a rod-shaped geometry that locates the two dendrons in opposite directions. $^{35}$ On the other hand, functionalization of the porphyrin core with the coumarin-containing dendrons gives rise to disk-like structures. ${ }^{36-38}$ Thus, the XRD pattern recorded

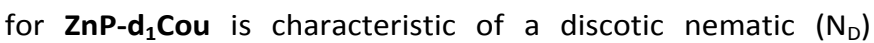
mesophase. It displayed one relatively strong reflection in the low-angle region corresponding to the presence of a certain degree of short-range columnar order within the nematic phase, as has been previously described in other $N_{D}$ phases, ${ }^{39-}$ ${ }^{41}$ and a broad halo in the high-angle region which corresponds to the liquid-like order of the disordered alkyl chains (Figure 4a). The calculated $d$-spacing ( $26 \AA$ ) for the signal in the lowangle region represents the average inter-disk distance and approximates the diameter of the porphyrin core. The spacing from the high-angle diffraction is $4.6 \AA$, which mainly originates from the liquid-like correlations between the conformationally disordered alkyl chains.

On the other hand, the XRD pattern of $\mathbf{Z n P}-\mathbf{d}_{\mathbf{2}}$ Cou only showed diffuse scattering in the low-angle region, and a broad diffuse halo in the high-angle region (Figure $\mathbf{4 b}$ ). This pattern also confirms the presence of a $N_{D}$ mesophase. ${ }^{42}$ It is noteworthy the disappearance of the intense maximum in the low-angle region in the XRD pattern of $\mathbf{Z n P}-\mathbf{d}_{\mathbf{2}} \mathrm{Cou}$ (Figure $\mathbf{4 c}$ ). The greater number of alkyl chains in $\mathbf{Z n P - d _ { 2 }} \mathbf{C o u}$ could be responsible for these differences of $\mathrm{XRD}$, since they may hinder the lateral disk-disk interactions between metalloporphyrin units, and consequently, prevent the formation of columnar alterations within the $N_{D}$ phase.

With ZnP-d $\mathbf{d}_{\mathbf{1}} \mathbf{C 1 2}$, the DSC curve showed an exothermic peak at 122 oC (cold crystallization) and an endothermic peak corresponding both to the crystal-to-mesophase transition and the transition from mesophase to isotropic liquid. These two transitions were observed by POM and detected as only one endothermic peak in the DSC which corresponds to the sum of the two transition peaks, and thus the nature of the mesophase could not be identified by XRD. These results confirm the key role of the coumarin terminal units in the mesogenic behavior of these materials leading to the apparition of the mesophase at room temperature and increasing significantly the mesophase range. Both features are fundamental parameters for their practical applications in organic electronics. (a)

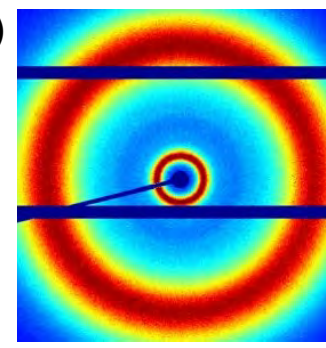

(b)

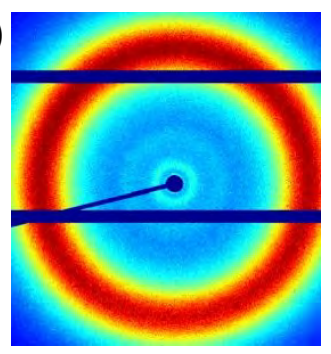

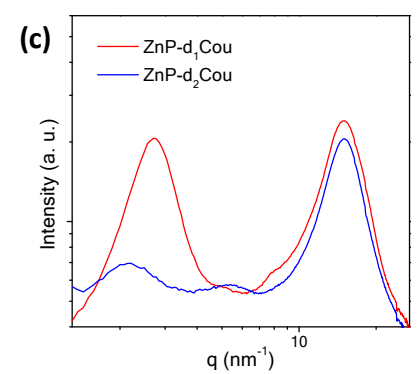

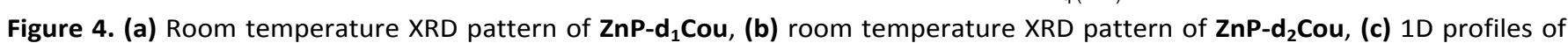
the XRD patterns. 
Table 2. Photophysical data in DCM solutions and in thin film.

\begin{tabular}{|c|c|c|c|c|c|c|c|c|c|}
\hline \multirow{3}{*}{ ZnP-YNE } & \multirow{3}{*}{$D C M$} & \multirow{3}{*}{$\begin{array}{c}\begin{array}{l}\lambda_{\mathrm{abs}}(\mathrm{nm}) \\
\text { Coumarin }\end{array} \\
-\end{array}$} & \multirow{3}{*}{$\begin{array}{c}\lambda_{\text {abs }}(\mathrm{nm}) \\
\text { Soret band } \\
426\end{array}$} & \multirow{3}{*}{$\begin{array}{l}\lambda_{\text {abs }}(\mathrm{nm}) \\
Q \text {-bands } \\
558,599\end{array}$} & \multirow{3}{*}{$\begin{array}{c}\lambda_{\mathrm{em}}(\mathrm{nm}) \\
\text { Coumarin }\end{array}$} & \multirow{3}{*}{$\begin{array}{c}\lambda_{\mathrm{em}}(\mathrm{nm}) \\
Q(0-1) \\
600\end{array}$} & \multirow{2}{*}{$\begin{array}{c}\lambda_{\mathrm{em}}(\mathrm{nm})^{D C} \\
Q(0-2)\end{array}$} & \multirow{2}{*}{$\begin{array}{l}: 10.10 \\
\Phi_{\mathrm{F}}[\mathrm{a}]\end{array}$} & \multirow{2}{*}{$\begin{array}{l}\text { /C8TC } \\
\Phi_{\mathrm{ET}}\end{array}$} \\
\hline & & & & & & & & & \\
\hline & & & & & & & 644 & 0.09 & - \\
\hline & film & - & 426 & 560,602 & - & 606 & 651 & - & - \\
\hline \multirow[t]{2}{*}{$\mathrm{N}_{3}-\mathrm{d}_{1} \mathrm{Cou}$} & $D C M$ & 324 & - & - & 388 & - & - & - & - \\
\hline & film & 314 & - & - & 411 & - & - & - & - \\
\hline \multirow[t]{2}{*}{$\mathrm{N}_{3}-\mathrm{d}_{2} \mathrm{Cou}$} & $D C M$ & 323 & - & - & 388 & - & - & - & - \\
\hline & film & 314 & - & - & 411 & - & - & - & - \\
\hline \multirow[t]{2}{*}{$\mathrm{ZnP}-\mathrm{d}_{1} \mathrm{Cou}$} & $D C M$ & 322 & 426 & 552,595 & 383 & 603 & 643 & 0.12 & $16 \%$ \\
\hline & film & 322 & 434 & 562,603 & $-[b]$ & 605 & 649 & - & - \\
\hline \multirow[t]{2}{*}{$\mathrm{ZnP}-\mathrm{d}_{\mathbf{2}} \mathrm{Cou}$} & $D C M$ & 321 & 427 & 552,594 & 383 & 601 & 642 & 0.11 & $23 \%$ \\
\hline & film & 322 & 436 & 563,604 & $-[b]$ & 605 & 648 & - & - \\
\hline \multirow[t]{2}{*}{$\mathrm{ZnP}-\mathrm{d}_{1} \mathrm{C} 12$} & $D C M$ & - & 417 & 540 & - & 600 & 644 & 0.14 & - \\
\hline & film & - & 424 & 544 & - & 611 & 650 & - & - \\
\hline
\end{tabular}

[a] The $\Phi_{\mathrm{F}}$ values were calculated from DCM solutions with tetraphenylporphyrin (0.11 in benzene) as standard, excitation at 420 nm. [b] Not detectable.

\section{Absorption and emission properties.}

The UV-Vis absorption and fluorescence spectra of porphyrincore dendrimers and precursors were collected on dilute solutions $\left(10^{-5}\right.$ to $\left.10^{-7} \mathrm{M}\right)$ in $\mathrm{DCM}$, and in thin films prepared by casting DCM solutions onto quartz substrates. Relevant data are presented in Table $\mathbf{2}$.

The two coumarin-containing dendritic precursors, $\mathbf{N}_{\mathbf{3}}-\mathbf{d}_{\mathbf{1}} \mathbf{C o u}$ and $\mathbf{N}_{\mathbf{3}}-\mathbf{d}_{\mathbf{2}} \mathbf{C o u}$, showed an absorption band in DCM solution at 324 and $323 \mathrm{~nm}$ respectively, and an emission band at $388 \mathrm{~nm}$. Interestingly, in thin film the absorption bands showed a hypochromic shift of about $10 \mathrm{~nm}$, while the emission band showed a significant bathochromic shift of $23 \mathrm{~nm}$ probably due to the aggregation effect. The porphyrin precursor ZnP-YNE showed in the UV-visible spectrum a Soret band at $426 \mathrm{~nm}$, and two $Q$ bands at 558 and $599 \mathrm{~nm}$. Excitation of the Soret band resulted in the apparition of two emission bands at 606 $(\mathrm{Q}(0-1))$ and $651 \mathrm{~nm}(\mathrm{Q}(0-2))$.

On the other hand, the UV-Vis absorption spectra of the three porphyrin-core dendrimers in DCM solution are, within experimental error, a combination of the spectra of the alkyne functionalized porphyrin and the corresponding azido functionalized dendron (Figure 5a). The absorption bands corresponding to the coumarin units showed similar values both in solution and in thin film, whereas the absorption bands corresponding to the porphyrin core in thin film exhibited a bathochromic shift of about $10 \mathrm{~nm}$ in relation to those in solution, due to the aggregation effect.

The fluorescence emission spectra of the three porphyrin-core dendrimers $\left(\lambda_{\text {exc }}=425 \mathrm{~nm}\right)$ consisted of two bands with a $\mathrm{Q}(0-$ 1)-band at around $600 \mathrm{~nm}$ and a Q(0-2)-band at around 645 $\mathrm{nm}$ (Figure 5a). The fluorescence quantum yields were also measured with tetraphenylporphyrin as standard $\left(\Phi_{\mathrm{F}}=0.11\right.$ in benzene), obtaining low quantum yields. The fluorescence spectra were also recorded in thin films. Compared to the data from DCM solutions, the emission $Q(0-1)$ and $Q(0-2)$ peaks are red-shifted ca. 5-10 $\mathrm{nm}$. (a)

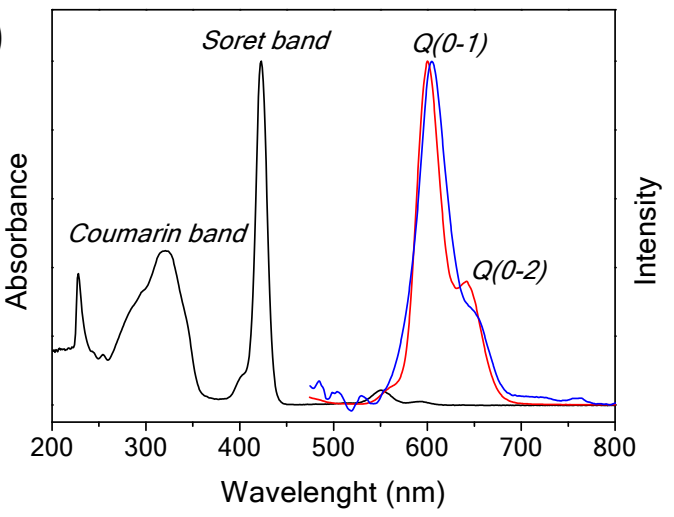

(b)



Figure 5. a) UV-Vis absorption spectra in DCM solution (black line) and emission spectra $\left(\lambda_{\text {exc }}=425 \mathrm{~nm}\right.$ ) in DCM solution (blue line) and in thin film (red line) of $\mathbf{Z n P}-\mathbf{d}_{1}$ Cou. b) UV-Vis absorption spectra in DCM solution (black line) and emission spectra $\left(\lambda_{\text {exc }}=320 \mathrm{~nm}\right.$ ) in DCM solution (blue line) and in thin film (red line) of $\mathbf{Z n P}-\mathbf{d}_{1}$ Cou.

Nonetheless, when peripheral coumarin units of the dendrimers were excited at $320 \mathrm{~nm}$, significant differences in 
the fluorescence emission spectra were observed between the measurements in DCM solution and in thin film. In the first case, the emission band at $388 \mathrm{~nm}$ (see blue line in Figure $\mathbf{5 b}$ ) slightly overlap the Soret absorption band of the porphyrin, and thus the porphyrin core was excited. As a consequence, emission from the porphyrin core was also observed, indicating that intramolecular energy transfer occurs from coumarins donors to the porphyrin acceptor (antenna effect). The energy transfer efficiencies $\left(\Phi_{E T}\right)$ were calculated by comparing the donor emission in the presence of the acceptor relative to that in the absence of the acceptor, ${ }^{43-45}$ and are summarized in Table 2 . Low $\Phi_{\mathrm{ET}}$ efficiencies were obtained because of the low degree of overlap between the emission spectrum of the coumarin and the absorption spectrum of the porphyrin. However, it is noteworthy that the $\Phi_{E T}$ value of the second generation dendrimer $\left(\mathbf{Z n P}-\mathbf{d}_{2} \mathbf{C o u}, \Phi_{E T}=23 \%\right)$ is higher than that of the first generation dendrimer (ZnP-d $\mathbf{d}_{\mathbf{1}} \mathrm{Cou}, \Phi_{E T}=$ $16 \%)$. This is probably because the higher number of peripheral coumarin units increase the effectivity of the lightharvesting.

The fluorescence spectra $\left(\lambda_{\text {exc }}=320 \mathrm{~nm}\right)$ were also recorded in thin film and compared to the data from DCM solutions; the coumarin emission band was totally suppressed and only emission from the porphyrin core was observed (see red line in Figure $\mathbf{5 b}$ ). Therefore, the energy transfer from coumarin units to the porphyrin core is more efficient in the thin film than in DCM solution. This behavior can be attributed both to a higher number of coumarin donors around porphyrin acceptors and to the anisotropic nature of the films.

\section{Electrochemical properties and hole mobilities.}

Cyclic voltammetry experiments (CV) were performed to study the electrochemical properties of the porphyrin-core

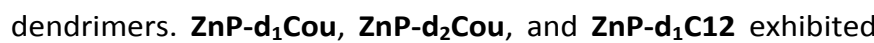
similar cyclic voltammograms with reduction and oxidation processes. The HOMO and LUMO energy levels, referred to the vacuum level were estimated from the oxidation and reduction waves (Table $\mathbf{3}$ )

Table 3. Electrochemical parameters and hole mobilities.

\begin{tabular}{lccc}
\hline & $E_{\text {HOMO }}(\mathrm{eV})^{[\mathrm{a}]}$ & $\begin{array}{l}\mathrm{E}_{\text {LUMO }} \\
(\mathrm{eV})^{[\mathrm{a}]}\end{array}$ & $\mu_{\text {hole }}\left(\mathrm{cm}^{2} \cdot \mathrm{V}^{-1} \cdot \mathrm{s}^{-1}\right)$ \\
\hline ZnP-d & & -1.33 & $0.15 \pm 0.05$ \\
ZnP-d & -4.92 & -1.33 & $0.9 \pm 0.2^{[\mathrm{b}]}$ \\
ZnP-d $_{\mathbf{1}}$ C12 & -4.94 & -1.35 & $(2 \pm 1) \times 10^{-9}$ \\
\hline
\end{tabular}

[a] $E_{\text {HOMO }}=-\left(E_{\text {ox }}-E_{1 / 2, \text { FOC }}+4.8\right)$ eV. $E_{\text {LUMO }}=-\left(E_{\text {red }}-E_{1 / 2, \text { FOC }}+\right.$ 4.8) eV. [b] Lower estimation of the charge carrier mobility (measured in areas with the lowest currents).

The charge carrier mobility measurements were performed by using the space charge-limited current (SCLC) technique. The SCLC method was chosen by considering the HOMO energy value of the materials, which matches the work function of gold electrodes $\left(W_{\mathrm{Au}} \approx-5.1 \mathrm{eV}\right)$ and thus ensures the formation of an ohmic contact. As a counter-electrode, indium tin oxide (ITO) was used because its work function $\left(W_{\text {ITO }} \approx-4.6 \mathrm{eV}\right)$ is significantly lower than the LUMO energy values and A $_{\text {because }}$ being transparent, it simplifies the Dobservationstgf61the macroscopic orientation by POM. All the cells, with a thickness in the $5-10 \mu \mathrm{m}$ range, were filled by capillarity by heating the material above the temperature of the transition to the isotropic liquid. After sample filling, cells were cooled to room

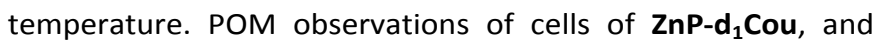
ZnP-d $\mathbf{d}_{2}$ Cou showed a strong tendency for homeotropic alignment. That is, without any surface treatment, the samples were perfectly oriented with the director (average direction the short molecular axes) perpendicular to the substrate.

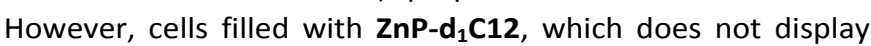
liquid crystal properties at room temperature, showed large crystalline domains of various orientations.

The current-voltage curves typically exhibited a linear region at low applied voltages, where the behavior is ohmic. However, at higher voltages, where the current becomes space-chargelimited, a quadratic dependence was observed. In this regime, neglecting the effect of traps and the voltage dependence of mobility, the current dependence on applied voltage is described by the Mott-Gurney equation: ${ }^{42}$

$J=\frac{9}{8} \varepsilon_{0} \varepsilon_{r} \mu \frac{V^{2}}{d^{3}}$

where $J$ is the measured current density, $\mu$ is the charge mobility, $\varepsilon_{0}$ is the free-space permittivity, $\varepsilon_{\mathrm{r}}$ is the dielectric constant of the material, $V$ is the applied voltage, and $d$ is the thickness of the device. As the relative dielectric constant and the sample thickness can be easily measured, by using this equation charge mobilities can be extracted from $J-V$ curves. The resulting hole mobilities values $\left(\mu_{\text {hole }}\right)$ are summarized in Table 3.

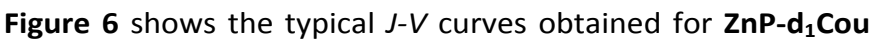
and $\mathbf{Z n P}-\mathbf{d}_{\mathbf{1}} \mathbf{C 1 2}$ and the resulting hole mobilities were $0.15 \pm 0.05$ and $(2 \pm 1) \times 10^{-9} \mathrm{~cm}^{2} \cdot \mathrm{V}^{-1} \cdot \mathrm{s}^{-1}$, respectively. The low

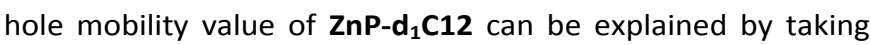
into account that this compound does not display liquid crystal properties at room temperature and thus all the measurements were carried out in macroscopically disordered crystalline phases. In the case of $\mathbf{Z n P}-\mathbf{d}_{\mathbf{1}} \mathbf{C o u}$, the introduction of coumarin units around the porphyrin core contributes to the appearance of the discotic nematic mesophase, leading to a remarkable increase of $\mu_{\text {hole }}$ by 8 orders of magnitude.
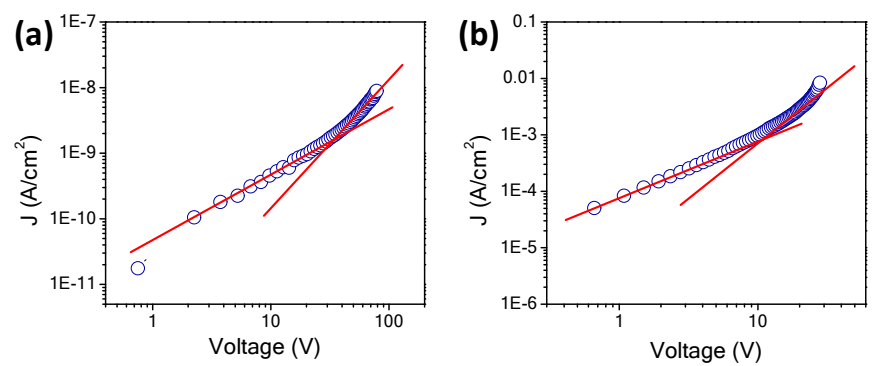

Figure 6. Typical J-V curves for: (a) ZnP-d $\mathbf{C l 1 2}_{1}$ and (b) ZnP$\mathbf{d}_{1} \mathbf{C o u}$ (circles represent experimental data and the two continuous lines represent ideal linear and quadratic dependence of $J$ on $V$ ). 
On the other hand, very high currents were measured for ZnP$\mathbf{d}_{\mathbf{2}}$ Cou. However, the hole mobility values reported in Table $\mathbf{3}$ were obtained only in those areas of the samples with the lowest currents. Within the areas exhibiting higher currents, an ohmic regime was observed at all applied voltages, probably because the injected charges never reach a density high enough for the set-up of the space-charge regime. Films


between ITO and Au electrodes were also prepared by spincoating followed by electrode evaporation, as described in the Supporting Information. However, also in this case only ohmic regimes and high currents were observed. This means that the charge mobility that was possible to measure via the SCLC technique is a lower estimation of the hole mobility in these materials and thus the real $\mu_{\text {hole }}$ is probably much higher.

The results obtained in these dendrimers reveal the key role played by the coumarin units in the hole mobility properties, either directly through an involvement in the hopping process, or indirectly through its promesogenic activity. Nevertheless, a definitive explanation for the different hole mobility values

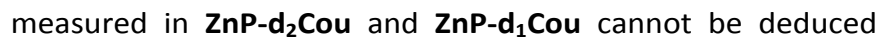
with the reported data. However, a hint might be derived from the XRD patterns that, as illustrated above, suggest the presence of a certain degree of short-range columnar order

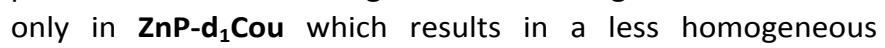
mesophase compared to $\mathbf{Z n P}-\mathbf{d}_{\mathbf{2}} \mathbf{C o u}$. Bearing in mind their spontaneous homeotropic alignment (i.e. a favorable macroscopic orientation between electrodes), a higher

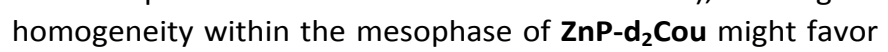
a more uniform alignment over large areas of the samples, leading to an increase of hole mobility. In addition, the higher number of coumarin units in $\mathbf{Z n P}-\mathbf{d}_{\mathbf{2}} \mathbf{C o u}$ could also play an enhancing role in the increase of the hole mobility values.

\section{Conclusions}

Herein, we have developed a convenient and highly versatile route involving 'click' chemistry to prepare novel liquid crystalline dendrimers based on a porphyrin core and coumarin units at the periphery of the dendrimer. In these compounds we have demonstrated that excitation of coumarin donors results in energy transfer to the porphyrin central core. This antenna effect is more efficient in thin film than in solution.

The peripheral coumarin units play a key role in the liquid crystal behavior, contributing to the appearance of discotic nematic mesophases with high hole mobility values (of the order of $\left.1 \mathrm{~cm}^{2} \cdot \mathrm{V}^{-1} \cdot \mathrm{s}^{-1}\right)$. To confirm this point a dendrimer analogue (i.e. without coumarin peripheral units) was prepared, and a decrease of 8 orders of magnitude in hole mobility was observed, stressing our hypothesis about the decisive influence of coumarin moieties in the final properties of the dendrimers. In general, the second generation dendrimer showed better optical (antenna effect) and electronic properties (hole mobility) than the first generation analogue. Thus, these results probe the importance of tuning such properties upon modification of dendrimer's generation.
In conclusion, we have found that combining nlina

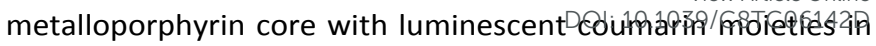
the same dendritic scaffold is a good strategy for the preparation of polymeric materials for optoelectronic applications. Particularly, the hole mobility values are one of the highest values reported for discotic liquid crystals to this date. Therefore, these porphyrin-core dendrimers have great potential as semiconducting soft materials with high hole mobility.

\section{Conflicts of interest}

There are no conflicts to declare.

\section{Acknowledgements}

This work was supported by the MINECO-FEDER funds (project CTQ2015-70174), Gobierno de Aragón-FSE (Research Group E04). Authors would like to acknowledge the use of the SAI (UZ) and CEQMA (UZ-CSIC) Services. A. Golemme is grateful for support from the ELIOTROPO project (PONO3PE_00092_2). R. Termine was supported by the MERAVIGLIE project (CUP J28C17000080006).

\section{References}

1. O. Ostroverkhova, Chem. Rev., 2016, 116, 13279-13412.

2. A. Saeki, Y. Koizumi, T. Aida and S. Seki, Acc. Chem. Res., 2012, 45, 1193-1202.

3. M. Mas-Torrent and C. Rovira, Chem. Rev., 2011, 111, 48334856.

4. L. Wang, G. Nan, X. Yang, Q. Peng, Q. Li and Z. Shuai, Chem. Soc. Rev., 2010, 39, 423-434.

5. J. Takeya, M. Yamagishi, Y. Tominari, R. Hirahara, Y. Nakazawa, T. Nishikawa, T. Kawase, T. Shimoda and S. Ogawa, Appl. Phys. Lett., 2007, 90, 102120.

6. W. Pisula, M. Zorn, J. Y. Chang, K. Müllen and R. Zentel, Macromol. Rapid Commun., 2009, 30, 1179-1202.

7. M. O'Neill and S. M. Kelly, Adv. Mater., 2011, 23, 566-584.

8. E. K. Fleischmann and R. Zentel, Angew. Chem. Int. Ed., 2013, 52, 8810-8827.

9. N. K. Minar, K. Hou, C. Westermeier, M. Döblinger, J. Schuster, F. C. Hanusch, B. Nickel, G. A. Ozin and T. Bein, Angew. Chem. Int. Ed., 2015, 54, 7577-7581.

10. T. Kato, M. Yoshio, T. Ichikawa, B. Soberats, H. Ohno and M. Funahashi, Nat. Rev. Mater., 2017, 2, 17001.

11. T. Kato, J. Uchida, T. Ichikawa and T. Sakamoto, Angew. Chem. Int. Ed., 2018, 57, 4355-4371.

12. Y. Zeng, L. Lu, T. Gao, Y. Feng, J.-F. Zheng, E.-Q. Chen and X.-K. Ren, Dyes Pigm., 2018, 152, 139-145.

13. K. P. Gan, M. Yoshio, Y. Sugihara and T. Kato, Chem. Sci., 2018, 9, 576-585.

14. Y. Hu, K.-Y. Wu, T. Zhu, P. Shen, Y. Zhou, X. Li, C.-L. Wang, Y. Tu and C. Y. Li, Angew. Chem. Int. Ed., 2018, 57, 13454-13458.

15. R. Chico, E. de Domingo, C. Domínguez, B. Donnio, B. Heinrich, R. Termine, A. Golemme, S. Coco and P. Espinet, Chem. Mater., 2017, 29, 7587-7595.

16. A. Benito-Hernández, U. K. Pandey, E. Cavero, R. Termine, E. 
M. García-Frutos, J. L. Serrano, A. Golemme and B. Gómez-Lor, Chem. Mater., 2013, 25, 117-121.

17. T. Sakurai, K. Tashiro, Y. Honsho, A. Saeki, S. Seki, A. Osuka, A. Muranaka, M. Uchiyama, J. Kim, S. Ha, K. Kato, M. Takata and T. Aida, J. Am. Chem. Soc., 2011, 133, 6537-6540.

18. E. M. García-Frutos, U. K. Pandey, R. Termine, A. Omenat, J. Barberá, J. L. Serrano, A. Golemme and B. Gómez-Lor, Angew. Chem. Int. Ed., 2011, 50, 7399-7402.

19. T. Sakurai, K. Shi, H. Sato, K. Tashiro, A. Osuka, A. Saeki, S. Seki, S. Tagawa, S. Sasaki, H. Masunaga, K. Osaka, M. Takata and T. Aida, J. Am. Chem. Soc., 2008, 130, 13812-13813.

20. A. Concellón, M. Marcos, P. Romero, J. L. Serrano, R. Termine and A. Golemme, Angew. Chem. Int. Ed., 2017, 56, 1259-1263.

21. X. Zeng, G. Ungar, Y. Liu, V. Percec, A. E. Dulcey and J. K. Hobbs, Nature, 2004, 428, 157.

22. B. Donnio, S. Buathong, I. Bury and D. Guillon, Chem. Soc. Rev., 2007, 36, 1495-1513.

23. B. M. Rosen, C. J. Wilson, D. A. Wilson, M. Peterca, M. R. Imam and V. Percec, Chem. Rev., 2009, 109, 6275-6540.

24. H. J. Sun, S. Zhang and V. Percec, Chem. Soc. Rev., 2015, 44, 3900-3923.

25. S. Hernández-Ainsa, M. Marcos and J. L. Serrano, in Handbook of Liquid Crystals, eds. J. W. Goodby, P. J. Collings, T. Kato, C. Tschierske, H. Gleeson and P. Raynes, Wiley-VCH Verlag GmbH \& Co. KGaA, Second edn., 2014, vol. 7, ch. 7, pp. 259-300.

26. A. Concellón, T. Liang, A. P. H. J. Schenning, J. L. Serrano, P. Romero and M. Marcos, J. Mater. Chem. C, 2018, 6, 10001007.

27. A. Concellón, M. Bucoş, J. L. Serrano, P. Romero and $M$. Marcos, RSC Adv., 2016, 6, 65179-65185.

28. V. Iguarbe, A. Concellón, R. Termine, A. Golemme, J. Barberá and J. L. Serrano, ACS Macro Lett., 2018, DOI: 10.1021/acsmacrolett.8b00505, 1138-1143.

29. A. Concellón, S. Hernández-Ainsa, J. Barberá, P. Romero, J. L. Serrano and M. Marcos, RSC Adv., 2018, 8, 37700-37706.

30. R. K. Iha, K. L. Wooley, A. M. Nyström, D. J. Burke, M. J. Kade and C. J. Hawker, Chem. Rev., 2009, 109, 5620-5686.

31. M. V. Walter and M. Malkoch, Chem. Soc. Rev., 2012, 41, 45934609.

32. M. Arseneault, C. Wafer and J. F. Morin, Molecules, 2015, 20, 9263.

33. S. Guerra, T. L. A. Nguyen, J. Furrer, J.-F. Nierengarten, J. Barberá and R. Deschenaux, Macromolecules, 2016, 49, 32223231.

34. A. Lancelot, R. González-Pastor, A. Concellón, T. Sierra, P. Martín-Duque and J. L. Serrano, Bioconjugate Chemistry, 2017 28, 1135-1150.

35. M. Marcos, R. Martín-Rapún, A. Omenat and J. L. Serrano, Chem. Soc. Rev., 2007, 36, 1889-1901.

36. B. Wu, K. Chen, Y. Deng, J. Chen, C. Liu, R. Cheng and D. Chen, Chem. Eur. J., 2015, 21, 3671-3681.

37. L. Li, S. W. Kang, J. Harden, Q. Sun, X. Zhou, L. Dai, A. Jakli, S. Kumar and Q. Li, Liq. Cryst., 2008, 35, 233-239.

38. A. Segade, M. Castella, F. López-Calahorra and D. Velasco, Chem. Mater., 2005, 17, 5366-5374.

39. C. T. Imrie, Z. Lu, S. J. Picken and Z. Yildirim, Chem. Commun., 2007, DOI: 10.1039/B614922G, 1245-1247.

40. M. Gupta, S. P. Gupta, M. V. Rasna, D. Adhikari, S. Dhara and S. K. Pal, Chem. Commun., 2017, 53, 3014-3017.

41. M. Gupta, S. P. Gupta, S. S. Mohapatra, S. Dhara and S. K. Pal, Chem. Eur. J., 2017, 23, 10626-10631.

42. H. K. Bisoyi and S. Kumar, Chem. Soc. Rev., 2010, 39, 264-285.
43. S. L. Gilat, A. Adronov and J. M. J. Fréchet, Angew Chem Int. Ed., 1999, 38, 1422-1427. DOI: 10.1039/C8TC06142D

44. A. Adronov, S. L. Gilat, J. M. J. Fréchet, K. Ohta, F. V. R. Neuwahl and G. R. Fleming, J. Am. Chem. Soc., 2000, 122, 1175-1185.

45. S. Hecht, N. Vladimirov and J. M. J. Fréchet, J. Am. Chem. Soc., 2001, 123, 18-25. 
High hole mobility and light-harvesting in discotic nematic dendrimers prepared via 'click' chemistry

Alberto Concellón, Roberto Termine, Attilio Golemme, Pilar Romero, Mercedes Marcos, and José Luis Serrano*

We have developed a new strategy involving 'click' chemistry to to prepare porphyrin-core dendrimers that have coumarin units around the porphyrin core. These dendrimers exhibit nematic discotic phases with hole mobilities among the highest values described in liquid crystals. Moreover, we have also demonstrated that excitation of the coumarin moieties leads to energy transfer (antenna effect) to the porphyrin core.



